\title{
Sea-birds: Their Relation to the Fisheries and Agriculture.
}

\section{By Dr. Walter E. Collinge.}

D URING the past few years there has been a growing opinion on the part of the general public and those connected with our fisheries that the enormous number of sea-birds on our coasts are inimical to the fisheries and to a less extent to agriculture. This view has been fostered to a large degree by the public expression of irresponsible statements and by the fact that we do not possess any exact and trustworthy knowledge of the nature of the food of these birds. Even amongst ornithologists and other students of wild-bird life widely divergent views are held.

Hitherto no investigation sufficiently comprehensive has been made, and in those cases where the birds of a restricted area have been studied, or where an insufficient number of specimens has been examined, the results have proved inconclusive, and, owing to the methods employed, to some extent misleading.

About two and a half years ago, under the auspices of the Carnegie Trust for the Universities of Scotland, an investigation was commenced in which it was proposed to examine large series of each species from numerous localities during each month of the year, and to estimate the food by the volumetric method. Although this research is not yet complete, sufficient data are in hand to warrant an expression of opinion upon this subject, and it is felt that such is highly desirable at the present time, when so many erroneous views are being circulated.

$\mathrm{U}_{\mathrm{p}}$ to the present, fourteen species have been examined, represented by upwards of three thousand specimens. The species are cormorant, shag, common gull, herring gull, great blackbacked gull, lesser black-backed gull, blackheaded gull, kittiwake, common tern, razorbill, guillemot, little auk, puffin, and great northern diver. Whilst it is not possible here to reproduce the numerous percentage tables showing the nature of the food for each species during the various months of the year, or those illustrating the seasonal variations or the percentages of the different species of fish destroyed, it is possible to make a general statement which we believe future work will more fully amplify and confirm.

First, we would point out that the importance and amount of fish that has been generally regarded as forming the diet of most of these birds are not borne out by an actual examination of their crop and stomach contents. Fish does not (with such exceptions mentioned later) constitute the bulk of their food or anything like the major portion of it. Indeed, one has only to watch carefully such species as the black-backed gull, the herring gull, and the lesser black-backed gull on the shore after the ebb of the tide to realise how essentially these birds are the scavengers of the shore. If they turn landwards, then injurious insects, earthworms, frogs, and carrion are greedily fed upon. Further, if one confines one's NO. 2632 , VOL. IO5] observations to birds drowned in the fishermen's nets, entirely misleading ideas are obtained, for these few birds constitute but the merest fraction of the huge bird population frequenting our coasts.

The above-mentioned fourteen species may be divided into three classes, viz.: (i) Purely fish feeders; (ii) largely fish feeders, but most of the fish are not utilised by man as food; (iii) fish feeders to less than 20 per cent. of the total bulk of their food. Most of the species fall into class (iii). In class (i) is placed the cormorant and shag, for, so far as observations go, their food consists entirely of fish, and chiefly of food fishes. In class (ii) is placed the common tern. The remaining eleven species must all be placed in class (iii).

From information obtained from various sources, there is a general consensus of opinion that the cormorant and the shag do an enormous amount of harm to the fisheries. Nothing can be advanced in their favour, though it is open to question whether our fish supply would show any increase even were these birds exterminated. Respecting the common tern, sand eels constitute fully 50 per cent. of its fish diet; the gunnel or butter fish, gobies, young gurnard, herring, and haddock are also taken.

It is not possible here to give the details of the analyses for all the remaining species; we shall therefore select one, the black-headed gull. More than five hundred specimens of this species have been examined, obtained from various localities and during each month of the year. This species is selected because it has increased enormously during the last twenty years, and is now generally regarded as one of the most injurious both to the fisheries and to agriculture.

Of the total bulk of food consumed in a year, 96 per cent. consists of animal matter, and 4 per cent. of vegetable matter. Of the former the actual amount of food fishes found was I I.5 per cent., and of other fishes (not utilised by man as food) 9 per cent., or a total fish diet of 20.5 per cent. Edible crustacea are present to the extent of 4 per cent., and other forms, non-edible, to that of Io per cent. Marine worms constitute I 8.5 per cent., molluses 4 per cent., echinoderms 2.5 per cent., injurious insects 22 per cent., other insects 1.5 per cent., earthworms Io per cent., and miscellaneous animal matter 3 per cent. Of the vegetable matter, 2.5 per cent. consists of cereals, and $\mathrm{I} \cdot 5$ per cent. of miscellaneous matter (Fig. I).

If the huge bulk of food from which these figures have been obtained means anything at all, it indicates clearly and definitely that this species is a highly beneficial one. By no reasonable deduction can it be shown to be otherwise, for nearly two-thirds of its food is of a neutral nature, viz. 60 per cent. ( 38 per cent. of which consists of shore refuse.) Only 18 per cent. is injurious, and 22 per cent. is highly beneficial. We 
feel certain that no one who has had experience in work of this character will for a moment question whether this percentage of food, which is conferring a benefit upon agriculture, balances the injury that is inflicted upon an inexhaustible and ever-increasing fish supply.

Very similar figures might be advanced for the remaining species, none of which are taking more than 20 per cent. of tish per annum of their total bulk of food. Is the sea so impoverished that we cannot afford these birds this amount of fish-food in exchange for their beneficial action in destroying more than 20 per cent. of injurious insects (of which 7.2 per cent. consist of wireworms in the case of the black-headed gull)?

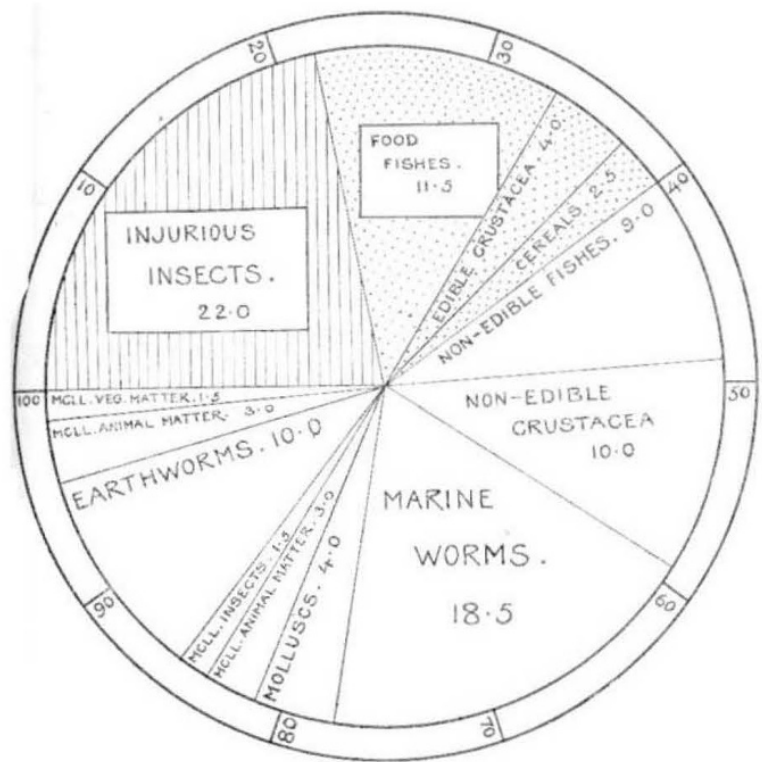

FIG. x.-Diagrammatic representation of the percentage of food of the black-headed gull. The portions shaded by longitudinal lines represent food that it is beneficial the birds should eat; those stippled, food that it is injurious they should eat, and the blank portions food of a neutral nature.

The records, both individually and collectively, show that the bulk of the food of these birds is not fish, but animal matter of a neutral nature. Of course, if one classes all annelids, non-edible crustacea, and molluscs as fish food, then very different figures may be obtained; but those who are acquainted with the abundance and the nature of the marine life cast up on the shore will agree with us in regarding these as a neutral factor.

If the figures are summarised for all the species in class (iii) (so far as our investigation has gone), the verdict is certainly in favour of these birds. It is very easy to condemn a species because at some particular season of the year or in some district a certain number have been found to be feeding upon food fishes; but, as has been frequently pointed out, such partial records do not give a true estimate of the food as a whole. It must not for one moment be thought that we are endeavouring to explain away the injuries inflicted, but we contend that it is unfair to judge any species of wild bird upon a local or partial record; the nature of the food generally throughout the United Kingdom and over the whole year is what we have endeavoured to learn.

Very interesting results have been obtained as to the seasonal changes of food and the variations in different localities. Sex and age also influence the quantity of food taken, and although the figures are yet incomplete, they point to the fact that the males take a larger quantity of food than the females, and the young birds more than the old.

It is not within the province of this inquiry to discuss the question of the impoverishment of the sea, but it will be impossible to conclude it without taking cognisance of the leading views on the subject and their bearing upon this question.

Finally, all the work goes to show that with a few exceptions-e.g. the cormorant and the shagthe food of each species is partly beneficial, and, even if for the moment we admit that the percentage of the fish destroyed is an injury, we must take into consideration the benefits derived by reason of the nature of the remaining food. This varies in different seasons of the year and according to the nature of the locality, but if an average is taken of the eleven species in class (iii), we find that the total percentage of injuries is less than that of the benefits, and that the bulk of the food is of a neutral nature.

It is obvious that, after examining upwards of three thousand specimens, with the results obtained, the question of the food of our commoner sea-birds and their effect upon the fisheries and agriculture can no longer remain where it was; and, whilst not advocating any special protection, except in one or two cases, any agitation for their destruction cannot be condemned too forcibly, for, altogether apart from sentimental reasons, it is extremely unlikely that our fisheries would benefit or show any marked improvement, even were hundreds of thousands of these birds destroyed annually, whilst agriculture would certainly be the sufferer by such a loss.

\section{The Imperial College of Science and Technology.}

THE Chancellor of the Exchequer, speaking in the House of Commons on March I6, expressed concern at the extraordinary expansion of business in the promotion of companies, and said he was convinced that the time had come when part of the money thus called for only creates increased competition for the limited supplies of labour and material which are all that are available. Few of us can doubt that this concern of the Chancellor is more than justified, but it is not only for purely industrial enterprise that appeals to the public at large are being made daily for large sums of money. Owing to the universal rise in prices, educational institutions

NO. 2632 , VOL. IO5] 